\title{
Product intelligence: its conceptualization, measurement and impact on consumer satisfaction
}

\author{
Serge A. Rijsdijk • Erik Jan Hultink • \\ Adamantios Diamantopoulos
}

Published online: 9 May 2007

(C) Academy of Marketing Science 2007

\begin{abstract}
In the last decade, companies have developed a large number of intelligent products. Due to the use of information technology, these products operate somewhat autonomously, cooperate with other products, or adapt to changing circumstances. Based on a literature review and interviews with practitioners, the present article conceptualizes product intelligence and describes a procedure to measure the construct. The article also explores the link of product intelligence to consumer satisfaction through the innovation attributes of relative advantage, compatibility, and complexity. The article considers practical and theoretical implications and identifies future research directions.
\end{abstract}

Keywords Product intelligence - Consumer satisfaction . Innovation adoption $\cdot$ Scale development

In recent years, there has been a trend to equip manufactured products with information technology (IT) in the form of microchips, software, sensors, and other advanced

\section{S. A. Rijsdijk ( $\triangle)$}

RSM Erasmus University,

Woudestein, Room T10-52, P.O. Box 1738

3000 DR Rotterdam, The Netherlands

e-mail: srijsdijk@rsm.nl

\section{E. J. Hultink}

Delft University of Technology,

Landbergstraat 15 ,

2628 CE Delft, The Netherlands

e-mail: e.j.hultink@io.tudelft.nl

\section{A. Diamantopoulos}

Universität Wien,

Bruenner Strasse 72,

1210 Vienna, Austria

e-mail: adamantios.diamantopoulos@univie.ac.at electronics. As a result, an increasing number of consumer products are 'intelligent'; they are able to collect, process and produce information and even 'think' for themselves. Well-known examples of such intelligent products are the following:

- AIBO ERS-210, a robotic dog, is a member of Sony's second generation of Entertainment Robots. This robotic dog can walk around, lie down and play with a ball. AIBO (which stands for Artificial Intelligent roBOt) recognizes up to 50 spoken words. LEDs (lightemitting diodes) on the robot's face and tail enable AIBO to show emotions such as happiness or anger. AIBO is also capable of learning. By petting the dog or saying 'good boy,' the owner can reinforce certain behaviors of the dog. The owner can also punish the dog by saying 'don't do that.' As a result, the dog will adapt its behavior to the owner's wishes over time. The Sony AIBO can be considered a market success. Within 6 months of its release in November 2000, Sony had already sold all 50,000 ERS-210 robot dogs it had produced (at $\$ 1,500$ a piece). More recent and advanced models of the AIBO continue to be successful, especially in Japan.

- In the summer of 2002, Electrolux introduced the world's first autonomous vacuum cleaner, the Trilobite. The machine uses a sonar system, four motors and sophisticated electronics to navigate. It has no problem avoiding collisions with other objects. When the batteries run low, the Trilobite automatically returns to the charging station. If the machine needs charging before it has completed the vacuuming, it will automatically resume cleaning once it is fully charged. The Trilobite costs around $\$ 1,500$. 
Both AIBO and the Trilobite owe most of their functionality to IT. Other examples of such products are personal digital assistants (PDAs), car navigation systems, cell phones and digital video cameras. Intelligent products show intelligence in that they have several new capabilities. This paper further explicates these capabilities such as the ability to operate autonomously, respond to their environment, cooperate with other products, and/or understand and produce speech. Such characteristics presumably improve the benefits enjoyed by the consumer when using intelligent products.

The increasing importance of intelligent products has been previously recognized in the marketing literature. Watson et al. (2002) lay a conceptual foundation for thinking about future marketing based on ubiquitous networks. Physical products will be equipped with information and communication technologies and form extensions of these networks. As such, they may fulfill critical tasks in, for example, personalizing the communication between firms and their customers (Watson et al. 2002). The Hewlett-Packard Laserjet 4100 is an example of a product that is able to do so. This printer is able to order its own new cartridges over the Internet. The increasing relevance of intelligent products was also indicated in an editorial on the future of the Journal of the Academy of Marketing Science. In this editorial, intelligent products were placed at the top of 15 themes that were expected to be important topics of study in the next 30 years (Zinkhan 2003).

Several leading institutes and companies have also recognized that intelligent products will become important in the near future and set up specialized laboratories to conduct research on the integration of IT into new consumer products and people's living environment. The Massachusetts Institute of Technology (MIT), for example, has set up the project of 'House- $n$ ', which has the ultimate goal to develop a house that adapts to people's needs and reacts to environmental influences. The " $n$ " represents adjectives such as "next generation" and "neural." The researchers envision a house with an electronic "nervous system" that learns the habits of those who live in it and assists in their living patterns. Microsoft and Philips have set up comparable projects named 'Easy Living' and 'HomeLab', respectively. Both projects serve the purpose of building and testing products that show characteristics such as wireless connectivity, speech technology and other advanced intelligent technologies.

Despite the above developments, no empirical evidence currently exists on whether and how product intelligence affects consumer evaluations in post purchase situations. This paper intends to fill a part of this gap. First, we provide a conceptualization of product intelligence, based both on the literature and exploratory interviews with practitioners. Second, we develop a conceptual framework where we hypothesize that product intelligence influences consumer satisfaction through innovation attributes (e.g., relative advantage, compatibility, complexity). Third, we develop a multi-item measure for operationalizing product intelligence and use it to test the conceptual framework.

\section{Conceptualizing product intelligence}

Intelligent products are products that contain IT in the form of, for example, microchips, software and sensors, and that are therefore able to collect, process, and produce information ${ }^{1}$. Intelligent products show a range of abilities that cannot be found in non-intelligent products; we collectively refer to these abilities as "product intelligence."

To further conceptualize product intelligence and gain an overview of these capabilities of intelligent products, we consulted two sources of information. First, we conducted exploratory face-to-face interviews with seven practitioners from five different companies. These companies were purposely selected because they were known to be involved in the development of technologically advanced products with intelligent characteristics. All respondents had a background in electrical engineering or artificial intelligence and were involved in new product development as engineers or R\&D managers. After an introduction on the purpose of the interview, respondents were asked: 'What is, in your opinion, product intelligence?' The remainder of the interviews was open and was used to gain insight into the experts' views on product intelligence. The second source of information was an extensive literature search from the disciplines of new product development, artificial intelligence, human-computer interaction, and software agents.

We subsequently analyzed the interview transcripts and searched for the abilities of intelligent products that were mentioned in the literature. These analyses lead to a conceptualization of product intelligence as consisting of six key dimensions ${ }^{2}$ : autonomy, ability to learn, reactivity, ability to cooperate, humanlike interaction, and personality. These six dimensions were selected because they were found both in the literature and in the interview data. Also, existing physical products had properties that matched one or more of these dimensions to a lesser or higher degree. The overall intelligence of a product is thus conceptualized

\footnotetext{
${ }^{1}$ Other authors also refer to such products as smart products (Bauer and Mead 1995; Dhebar 1996).

${ }^{2}$ At first, our conceptualization also contained a seventh potential dimension: multifunctionality. However, suggestions of anonymous reviewers and the subsequent study conducted among intelligent product experts (see the "operationalization of product intelligence" section) indicated that multifunctionality should not be considered as a dimension of product intelligence.
} 
as the extent to which it possesses each of these dimensions. In our conceptualization, we consider the dimensions as distinct from each other and view product intelligence as a multidimensional, second-order construct that is formed by the six dimensions described below.

\section{Autonomy}

The first intelligence dimension of autonomy refers to the extent to which a product is able to operate in an independent and goal-directed way without interference of the user (Baber 1996). The experts that were interviewed in this phase of the study also mentioned the dimension of autonomy. One of the experts noted: "Intelligent products are products that can overtake daily activities and concerns from their user." An example of an autonomous product is the Automower of the Swedish firm Husqvarna. This lawnmower is placed on the lawn after which it moves through the garden and cuts the grass all by itself. By setting the limits of the lawn with a metal wire, the owner ensures that the lawnmower will remain within the area that should be mowed. Another example of an autonomous product is the Trilobite vacuum cleaner developed by Electrolux.

\section{Ability to learn}

Ability to learn is the second dimension and refers to a product's ability to improve the match between its functioning and its environment (Nicoll 1999). In the software agent literature, authors distinguish between 'deliberative' and 'reactive' agents. Deliberative agents collect and store information on their environment and use this information to build an internal model that represents this environment. This internal model is used when these agents perform complex decision-making tasks (Nwana and Ndumu 1997). The decisions that deliberative agents make depend on their environment and may vary along with changes in this environment. Reactive agents, on the other hand, react to an event in their environment without consulting an internal model and act using a stimulus/ response type of behavior (Nwana and Ndumu 1997). The actions of reactive agents to a certain event are the same in different environments and also remain the same over time. Analogous to the distinction between deliberative and reactive agents, we discriminate between the dimensions of 'ability to learn' and 'reactivity' (see below) in intelligent products. The ability to learn refers to the ability of a product to store information and consequently adapt to its environment (e.g., its user or the room in which it is placed) over time, which may result in better performance. Products that can learn are generally programmed with algorithms that use data that is collected over time, and influence the manner in which a product operates. One example of such a product is the Chronotherm thermostat developed by Honeywell. From the moment of installation, the Chronotherm collects data on the time it takes to raise the temperature in a room. While doing this, the device also takes into account the outdoor temperature. When the user instructs the thermostat to reach a certain room temperature at a certain time, the device will do so on the basis of the data it previously collected. The dimension of ability to learn also came forward in the expert interviews. For example, one of the interviewed engineers stated: "The ultimate product intelligence is learning from experience."

\section{Reactivity}

Reactivity is the third dimension of intelligence and refers to the ability of a product to react to changes in its environment in a stimulus/response manner (Bradshaw 1997). A good example of a product that is reactive is the Philips Hydraprotect hairdryer. This hairdryer lowers the temperature of the air when the humidity of the hair decreases, thereby preventing damage to the hair caused by hot air. Reactivity can be distinguished from the ability to learn in that reactivity refers to instant reactions to the environment. In contrast to the ability to learn, no internal models of the environment are needed for these reactions and reactions are constant over time. In one of the expert interviews, a respondent addressed reactivity describing an intelligent product as "a product that observes something and takes action on the basis of that observation."

\section{Ability to cooperate}

The fourth dimension of product intelligence is the ability to cooperate with other devices to achieve a common goal. According to Nicoll (1999), the age of discrete products may be ending. Instead, products are becoming more and more like modules with in-built assumptions of their relationships with both users and other products. An increasing number of products are thus able to communicate not only with their users, but also among themselves (Nicoll 1999). For example, desktop computers cooperate with other products; they can be attached to scanners, printers, musical instruments, video cameras and so on. Other obvious examples of products that can cooperate are mobile phones and PDAs. The user of these products can write emails on the PDA and send these via the mobile phone. One interviewee also observed that intelligent products are frequently able to cooperate: "Something that you see quite often in intelligent products is communication between separate products. One day it will be possible to interconnect all products." 
Humanlike interaction

The fifth dimension, humanlike interaction, concerns the degree to which the product communicates and interacts with the user in a natural, human way. Within the context of agents, Bradshaw (1997) speaks of 'knowledge communication ability' that refers to an agent's ability to communicate with persons and other agents with language resembling human-like 'speech acts'. Similarly, intelligent products are sometimes able to communicate with their users through voice production and recognition. For example, car navigation systems produce speech and some of them also understand speech. There is no need for users to push any buttons during driving and the driver is guided to his/her destination through a dialogue with the navigation system.

\section{Personality}

The last dimension, personality, refers to an intelligent product's ability to show the properties of a credible character. This dimension was also distilled from the literature on software agents in which Bradshaw (1997) discusses the property of an agent to have a 'believable personality and emotional state.' Well-known examples of agents with personality are the paperclip- or Einstein assistants in Microsoft Office that suggest that 'someone' assists the users. Physical products can also be equipped with an interface that shows personality characteristics. Levels of personality vary from interfaces showing only a caricature face to interfaces with the ability to show emotions (Cassell and Thorisson 1999). An example of an intelligent product in the marketplace with a high level of personality is Sony's AIBO that can be angry, happy or sad.

Distinctiveness of the product intelligence dimensions

As previously stated, the six dimensions are considered to be distinct. Intelligent products may show characteristics that match one intelligence dimension, but they may also match all dimensions simultaneously. Also, none of the dimensions precludes another dimension. For example, intelligent products can be either reactive or able to learn or both. Thus, an autonomous vacuum cleaner can also be reactive in that it does not collide into other objects; simultaneously, the vacuum cleaner may be able to learn the most efficient route through the house over time. However, autonomous vacuum cleaners without the ability to learn exist as well. Also, a product may be autonomous and simultaneously able to cooperate with other products. For example, a washing machine may be autonomous in that it chooses which detergent to use and which program to run. Simultaneously, the washing machine may be operated through the Internet or using a mobile phone. However, a washing machine that shows neither of these characteristics may be designed as well.

Despite the distinctiveness of the dimensions, we do not assume that the dimensions are unrelated. It is possible that, when a product is intelligent in terms of one dimension, it may also possess properties that match another. Once a product contains IT components, it has the basis to be equipped with characteristics and functionality that match one or more of the intelligence dimensions. Overall and as also confirmed by the exploratory interviews, we do not perceive trade-offs between the different intelligence dimensions and do not expect that the emphasis on one dimension may negatively affect other dimensions. On the contrary, we think that different intelligence dimensions may occur simultaneously.

\section{Conceptual framework}

The importance of product intelligence has been recognized in the marketing literature (Watson et al. 2002; Zinkhan 2003). Experimental studies have also been performed on how consumers respond to specific dimensions of product intelligence (see e.g., Chan and Khalid 2003; Rijsdijk and Hultink 2003). However, so far, no empirical field research has been conducted on how the overall construct of product intelligence is related to other marketing constructs in postpurchase situations. The current study aims to fill a part of this gap and hypothesizes that product intelligence is indirectly related to consumer satisfaction. Specifically, we expect that this relationship will be mediated by both positive and negative consequences of product intelligence. Owners of consumer products with higher levels of product intelligence are expected to perceive their products as offering more relative advantage and greater compatibility. At the same time, however, we expect that higher levels of product intelligence will lead consumers to perceive these products as more difficult to understand and use. We elaborate on these issues when developing our hypotheses below.

Product intelligence, innovation attributes and consumer satisfaction

Consumer satisfaction is one of the most widely studied constructs in marketing research (see e.g., Homburg and Stock 2004) and is described as a consumer's affective evaluation of a product or service. Consumer satisfaction is also frequently described as the extent to which the chosen product meets or exceeds consumer expectations. Oliver (1993) showed that these perspectives are complementary for a more complete understanding of consumer satisfaction 
(dissatisfaction); the latter has important behavioral consequences such as repurchase behavior, word-of-mouth communication and complaint behavior (Szymanski and Henard 2001).

We pose that product intelligence indirectly leads to consumer satisfaction, through the perceived innovation attributes of relative advantage, compatibility and complexity taken from the diffusion literature. Relative advantage is defined as the degree to which an innovation is perceived as superior to the idea it supersedes (Rogers 1995). An innovation can be superior in terms of economic profitability, social prestige, convenience, or other benefits. Compatibility is the degree to which an innovation is perceived as consistent with existing values, past experiences, and needs of potential adopters (Rogers 1995). A product that is more compatible fits more closely with the individual's way of living than a product that is less compatible. The complexity of an innovation concerns the degree to which an innovation is perceived as relatively difficult to understand and use (Rogers 1995).

Relative advantage, compatibility and complexity are the three most important (out of five) attributes from the innovation adoption literature that either positively (relative advantage, compatibility, observability and trialability) or negatively (complexity) affect the rate of adoption (Rogers 1995). In this context, a meta-study by Tornatzky and Klein (1982) showed that only the innovation attributes of relative advantage, compatibility and complexity consistently influenced innovation adoption. Also, previous research showed that these three innovation attributes play more important roles for purchase intention and innovation adoption than observability and trialability (Plouffe et al. 2001). Moreover, observability and trialability played an insignificant role for consumers that already gained experience in the use of a certain innovation (Plouffe et al. 2001). As such, we only consider the innovation attributes of relative advantage, compatibility, and complexity as relevant for our study.

We expect product intelligence to influence consumer satisfaction through the innovation attributes of relative advantage, compatibility, and complexity because it is consumers' perceptions that eventually determine the emotional evaluation of a product and not the product characteristics (here, the intelligence dimensions) themselves. In the diffusion literature, for example, the perceptions of potential adopters determine whether an innovation will be adopted (Rogers 1995). Comparably, consumer satisfaction is generally considered as the outcome of consumer perceptions. For example, Spreng and Olshausky (1993) empirically showed that consumer satisfaction is caused by the perceived performance of a product, while Fornell et al. (1996) found that consumer satisfaction was determined by perceived value and perceived quality. As such, we expect that the perceived innovation attributes will mediate the relationship between product intelligence and consumer satisfaction. In the case of the previously mentioned Electrolux Trilobite, for example, a sonar system is one of the vacuum cleaner's intelligent product characteristics that make it reactive. This reactivity results in consumer perceptions of a certain relative advantage, compatibility and complexity which, in turn, deliver a degree of consumer satisfaction. Thus, it is not the reactivity itself that leads to consumer satisfaction, but what it delivers (namely the ability of the vacuum cleaner to move through a room avoiding other objects).

In light of the above, we hypothesize that product intelligence increases consumer satisfaction indirectly through its impact on the innovation attributes of relative advantage, compatibility and complexity. Thus,

H1a: The relationship between product intelligence and consumer satisfaction is mediated by perceived relative advantage

$\mathrm{H} 1 \mathrm{~b}$ : The relationship between product intelligence and consumer satisfaction is mediated by perceived compatibility

H1c: The relationship between product intelligence and consumer satisfaction is mediated by perceived complexity

Product intelligence, relative advantage, compatibility and complexity

In this section we focus on the innovation attributes of relative advantage, compatibility and complexity and the way in which they are affected by product intelligence. The hypothesized relationships are developed using sources concerning the various intelligence dimensions and/or overall product intelligence. However, as the expected relationships are similar for the six dimensions, hypotheses are formally specified at the level of the overall construct of product intelligence.

As already stated, relative advantage concerns an innovation's perceived superiority to the idea it supersedes (Rogers 1995). We expect that more intelligent products will generally be perceived as offering more relative advantage. More specifically, focusing on the dimension of autonomy, Rijsdijk and Hultink (2003) showed that higher levels of autonomy increase the level of advantage that consumers perceive. This finding is in accordance with the expectations of Baber (1996) who described that higher levels of autonomy deliver savings in time and effort.

We also expect that products that are able to learn will be perceived as more advantageous. TV's could, for example, gain a higher relative advantage by being able to provide a 
viewer with personal recommendations. Such recommendations could be based on information about which type of viewer uses the TV or on the basis of personal profiles (Murasaki 2001). Comparably, products with a higher reactivity are also likely to be perceived as offering more advantage. For example, a door that opens when someone approaches it has the advantage over non-reactive doors in that people do not have to use muscle force to open it.

Products that are able to cooperate with a larger number of products also deliver more relative advantage. Previous research (see e.g., Katz and Shapiro 1985) showed that, for network products, utility strongly depends on the number of other users that are in the same network. (e.g., for a telephone, the utility that a consumer derives from purchasing the product depends on the number of other households or businesses that are in the same telephone network). Analogous to that, we expect that higher levels of ability to cooperate will also be associated with higher utility because they enable the product to cooperate with a larger number of products. For example, a PDA that is able to communicate with both mobile telephones and personal computers has a higher relative advantage than a PDA that can only communicate with a mobile phone.

Products that communicate in a more humanlike way and that show more personality characteristics are also expected to offer more advantage. In a study comparing different interfaces, Burgoon et al. (2000) showed that respondents rated the anthropomorphic interface that incorporated animated characters and speech synthesis as the most useful. In addition, using products that interact in a more humanlike way will be perceived as more convenient. For instance, Chan and Khalid (2003) showed that, compared to the use of a normal ATM, operating an ATM using voice control was evaluated as more fun. Given that the effects of the different intelligence dimensions on relative advantage are all expected to be positive, we hypothesize the following for the overall intelligence construct:

$\mathrm{H} 2 \mathrm{a}$ Product intelligence is positively related to perceived relative advantage.

Compatibility concerns the degree to which an innovation is perceived as being consistent with existing values, past experiences, and needs of potential adopters (Rogers 1995). We expect that more intelligent products will generally be perceived as more compatible. First, products with higher levels of autonomy are likely to be perceived as more compatible. Baber (1996) described how highly autonomous products may achieve a level of symbiosis in which there is a perfect match between the actions of the product's owner and what the product does. At this level of autonomy the presence of certain products may even become unnoticed. For example, a vacuum cleaner at this level of symbiosis would start its work when there is nobody in the house and stop its work when someone comes in.

In addition, products that are better able to learn are likely to be perceived as more compatible with consumer needs. In fact, a basic idea behind the construction of, for example, user profiles is to have a product better match this user's needs. The better a product is able to learn, the more accurate a user profile becomes (Waern 2004); as such, the product will be considered as more compatible.

More reactive products are also likely to be considered as more compatible in that they respond to their users. For example, the reactive Hydraprotect hairdryer that was described previously reacts to the humidity of the hair by lowering the temperature of the air. Similarly, properly functioning reactive toilets flush when needed, doors open when someone approaches, and lights switch on when a person enters the room.

The more a product is able to cooperate with other products, the more it can be embedded within a network of other products that a consumer already owns. The functionality of the products within this network might be enhanced when a consumer purchases another product that can communicate with the products already in the network. As such, a PDA that would be able to cooperate with both a mobile telephone and a personal computer that are already in the network is more likely to be perceived as more congruent with the consumer's needs than a PDA that can only communicate with a mobile phone.

Finally, we expect products that are able to communicate in a humanlike manner and that show personality characteristics to be more compatible with their users. Such products allow a form of interaction that more closely resembles interaction between humans. For example, in their study on the operation of an ATM, Chan and Khalid (2003) found that consumers evaluate the use of speech as more natural. Such findings can be explained by the fact that users can apply their knowledge about human conversation to their interaction with the product (Cassell and Thorisson 1999). Overall, we expect that products with higher levels of intelligence will be better tailored to the needs of consumers. Whereas non-intelligent products are more likely to demand the consumer to adapt to the product, more intelligent products are better adapted to the consumer. We thus hypothesize that:

$\mathrm{H} 2 \mathrm{~b}$ Product intelligence is positively related to perceived compatibility.

Complexity concerns the degree to which an innovation is perceived to be difficult to understand and use (Rogers 1995). We expect that intelligence products will be perceived as more complex. We also expect that this complexity will play a role both when consumers start 
using a product and when they have used the product over a period of time.

Several studies have shown that users of intelligent products perceive these products as complex. Chan and Khalid (2003), for example, found that users did not only experience the voice controlled ATM as more fun and natural, but also as difficult to learn. Also, Sproull et al. (1996) found that the users of an interface that showed personality in the form of a human face were less confident than users operating a text interface. In addition, Alpert et al. (2003) found that users of a user-adaptive interface had difficulty to understand how it worked.

Besides the complexity that will be perceived at first, we also expect consumers to perceive complexity in intelligent products in later phases of use. Due to the use of IT elements, most functionality of intelligent products is hidden inside a black box (Bauer and Mead 1995). Norman (1998) stated "as technology has advanced, we have understood less and less about the inner workings of the systems under our control." A pair of scissors, for example, is easy to use because all operating parts are visible and the implications are clear. The holes in the scissors have a size so that only fingers will fit and the number of possible actions with the scissors is limited (Norman 1998). For intelligent products this is not the case. Intelligent products can be considered as some of today's most technologically advanced products and many consumers may have difficulty understanding and using these products (Bauer and Mead 1995). This is partly due to the fact that users do not receive feedback in the form of movements or noise when using these products; processors and memory chips do their work invisibly and silently (Den Buurman 1997).

Several examples illustrate the complexity of intelligent products. For example, only a minority of the owners of video-recorders can program these devices for delayed recording. Also, users experience major problems when they have to reset channels on their TV sets and many functions permanently remain untouched (Den Buurman 1997). Some users do not even know that certain functions exist while, in other cases, consumers give up on using certain functions because their operation is too difficult to learn and use (Han et al. 2001). In short, we expect that:

$\mathrm{H} 2 \mathrm{c}$ Product intelligence is positively related to perceived complexity.

Relative advantage, compatibility, complexity and consumer satisfaction

The innovation attributes of relative advantage, compatibility and complexity are expected to directly affect consumer satisfaction. We base these expectations on existing literature. With respect to relative advantage, the adoption literature shows that relative advantage is positively related to adoption (Rogers 1995). Also, relative advantage increases the rate of diffusion of innovations and adopters spread a more positive word of mouth about innovations with a higher relative advantage (Rogers 1995). For the specific effect of relative advantage on consumer satisfaction, we draw a parallel with the utilitarian component that was related to satisfaction by Mano and Oliver (1993). Their study showed that utility was highly correlated with satisfaction. In addition, Fornell et al. (1996) showed that perceived value is positively associated with satisfaction.

With respect to the innovation attribute of compatibility, Rogers (1995) states that the compatibility of an innovation, as perceived by the members of a social system, is positively related to its rate of adoption. Several consumer satisfaction studies investigated the effect of the analogous variable of needs congruency, which concerns the degree to which a product matches a consumer's needs (Wirtz and Mattila 2001). These studies have shown that the extent to which a product matches consumer needs has a positive effect on consumer satisfaction (Spreng and Olshavsky 1993). Finally, Rogers (1995) states that the perceived complexity of an innovation is negatively related to its rate of adoption. This relationship has found support in multiple empirical studies involving different product categories (see e.g., Plouffe et al. 2001; Tornatzky and Klein 1982).

In light of the above, the following hypotheses are offered concerning the relationship between the three innovation attributes and consumer satisfaction:

H3a: Relative advantage is positively related to consumer satisfaction

$\mathrm{H} 3 \mathrm{~b}$ : Compatibility is positively related to consumer satisfaction

H3c: Complexity is negatively related to consumer satisfaction.

\section{Operationalization of the product intelligence construct}

As already stated, our conceptualization of product intelligence views it as a second-order construct that is formed as a combination of the six intelligence dimensions (i.e., autonomy, ability to learn, reactivity, ability to cooperate, humanlike interaction, and personality). Thus, the dimensions are seen as defining characteristics of the construct (Jarvis et al. 2003) and it is changes in the dimensions that are expected to cause changes in the construct, not the other way round; an increase in any dimension (irrespective of whether it is accompanied by an increase in the other dimensions or not) will result in an increase in overall product intelligence. 
Specifically, and consistent with the above conceptualization, we apply the 'aggregate model' of Law et al. (1998) to link the (second-order) construct of product intelligence to its (first-order) constituent dimensions. According to the aggregate model, 'the multidimensional construct is formed as an algebraic composite of its dimensions. The multidimensional construct can be a linear or a non-linear function of its dimensions, and the dimensions may also have unit weights or differential weights while forming the overall construct (Law et al. 1998, p. 745). We operationalize the overall extent of product intelligence as a weighted linear combination of the six dimensions, because a series of interviews among intelligent product experts showed that the intelligence dimensions vary in importance for the overall intelligence construct $^{3}$.

Weighing the dimensions To gain insight into the relative importance of the six dimensions for the overall extent of product intelligence, we gathered information from intelligent product experts. First, a pilot study was conducted in which three experts provided general comments on our conceptualization of product intelligence and the questions subsequently asked in the main interview study. Subsequently, we conducted interviews with 14 experts in order to determine the weights for the different dimensions. The specific individuals were selected because they worked on intelligent product design projects or intelligent product research projects. The experts had 2 to 15 years of experience in the field of intelligent products with an average of 7.5 years.

In the interviews, the 14 experts were presented with information on the product intelligence construct on a laptop computer. First, the conceptualization of product intelligence was presented by showing descriptions of the product intelligence dimensions and product examples illustrating the dimensions. Next, the experts were asked to rate each dimension on how important they considered it for the overall product intelligence construct; a seven-point scale ranging from $1=$ 'totally unimportant' to $7=$ 'very important' was used for this purpose. Finally, the experts were interviewed on the ratings they had provided in order to get a more in-depth view of their ideas on the product intelligence dimensions.

Table 1 shows the mean ratings and standard deviations for the six intelligence dimensions. We calculated the intraclass correlation (ICC) as an indicator for the level of agreement across the experts. More specifically, we computed the ICC for "Case 2, $k$ " as described by Shrout and Fleiss (1979). This specific ICC is most appropriate for

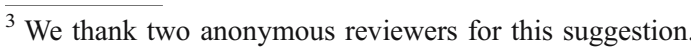

our design in which all experts (chosen from a larger population of experts) rate each dimension. The ICC computed over the ratings is 0.97 , with a $95 \%$ confidence interval running from 0.91 to 0.99 . As an ICC of 1.00 would indicate perfect agreement, we can consider the level of agreement among the experts as very high. Furthermore, we conducted a Post hoc Scheffé test to investigate whether the raters formed a homogeneous set with respect to their average ratings over all dimensions. The results showed that the experts do vary slightly but not significantly in their ratings ( $p$-value $=0.43$ ) and can thus be considered as a homogeneous set.

Considering the high agreement among experts on the importance of the dimensions, we calculated a weight for each dimension using the mean importance ratings (see Table 1).

The weights show that ability to learn and autonomy are considered as the most important dimensions with respective weights of 6.57 and 6.14 . From the interviews, it also became clear that most experts considered these dimensions as "the ultimate intelligence." For example, one expert described the ability to learn as "an essential part of product intelligence" while autonomy was described as "close to a condition for a product to be intelligent." With a weight of 5.07 and 5.21, respectively, the ability to cooperate and reactivity are also considered as relatively important. The importance of the ability to cooperate was clearly expressed by one expert stating "an intelligent product can work alone, but can increase its intelligence by being able to cooperate with other products and exchange information with them." Reactivity was also described as "quite important" and as "contributing to product intelligence". The dimensions of humanlike interaction and personality, on the other hand, were considered as moderately important. According to one of the experts, "natural interaction and the use of emotions is important in the interaction with products, but not essential for a product to be intelligent." In our operationalization of the overall product intelligence, we therefore weigh the six dimensions as shown in Table 1.

Table 1 Means and standard deviations for the expert ratings on the intelligence dimensions $(n=14)$

\begin{tabular}{lcc}
\hline Dimension & Mean $^{\mathrm{a}}$ & $\mathrm{SD}$ \\
\hline Autonomy & 6.14 & 0.86 \\
Ability to learn & 6.57 & 0.76 \\
Reactivity & 5.21 & 1.12 \\
Ability to Cooperate & 5.07 & 1.38 \\
Humanlike Interaction & 3.74 & 1.34 \\
Personality & 4.00 & 1.36 \\
\hline
\end{tabular}

${ }^{\mathrm{a}}$ Means are based on a seven-point scale where $1=$ "Totally

Unimportant" and 7 = "Very Important" 
Shifting attention to the operationalization of the individual intelligence dimensions, we view each dimension as a single latent variable reflected in a number of (imperfect) indicators. We opt for a conventional reflective measurement perspective to operationalize each dimension in order to ensure that, within a dimension, indicators share a common theme and thus reflect the same underlying construct (Jarvis et al. 2003). In summary, product intelligence is measured as a second-order construct with six (formative) first-order dimensions, with each of the latter being measured by means of reflective indicators. Thus, in generating our empirical measure of product intelligence it is necessary to (a) generate unidimensional and reliable multi-item scales for each dimension, and (b) weigh all scales and linearly combine them to derive an aggregate 'intelligence' score.

Item generation Based on an extensive literature review and consultation of the exploratory interview material, two independent researchers initially generated items for each of the six dimensions of product intelligence. Subsequently, another four researchers independently generated additional items in a brainstorm session. In this session, the researchers were provided with descriptions of the six dimensions of product intelligence, and a number of product examples illustrating each dimension. A total of 121 items were generated by these procedures. Subsequently, three pretests were conducted to purify the initial set of 121 items.

First pretest As an initial pretest, three undergraduate product design students and two marketing PhD students judged the set of 121 items. The judges were provided with descriptions of the six intelligence dimensions and each dimension was illustrated by two short product descriptions. The judges assigned each item to one of the six dimensions. The judges also commented on unclear and ambiguous items and came up with suggestions on how existing items might be improved. The judges also provided a number of new items. From the initial list of 121 items, 13 items were dropped, 27 items were edited, and 6 new items were added. Overall, this resulted in a revised item pool of 114 items.

Second pretest In a second pretest, we further determined the content validity of the items. Specifically, descriptions of the dimensions of product intelligence and corresponding product examples were provided to the judges (seven faculty members and three undergraduate students). The 114 items were printed on cards and given to the judges in a random order. The judges independently assigned each item to the dimension they thought it represented best. Only when all judges correctly assigned items to their corresponding dimension, were the items retained in the item pool. As a result of this procedure, 3 items were edited and 35 items were removed, resulting in a reduced set of 79 items.

Third pretest To test items on the extent to which they were scored consistently by different raters and to assess their ability to discriminate between products scoring high or low on the six dimensions of product intelligence, a third pretest was conducted. A total of 37 product design students evaluated three descriptions of intelligent products on the 79 remaining items using seven-point Likert scales. The three products presented each of the six dimensions to a lower or higher degree to evoke a variation in the way the items were rated. The three product descriptions concerned an intelligent refrigerator, thermostat, and car navigation system. The refrigerator was able to order groceries on its own (autonomy), and could function as a cooking-assistant (personality). The thermostat was able to learn how fast the temperature in a room could be raised (ability to learn) and reacted to changes in the outdoor temperature (reactivity). The car navigation system could not only guide a driver, but also send emails via a mobile telephone (ability to cooperate). In addition, the navigation system was able to both produce and recognize speech (humanlike interaction).

We calculated two types of standard deviations to determine the quality of each item. First, the standard deviation of each item over the different products was computed. Second, we calculated the standard deviation of the item over the different respondents. The standard deviation over the different products is an indicator of the item's sensitivity to differences across products. The standard deviation over the different respondents is an indicator of how consistent different respondents rate this item for the same product. Items with a relatively high standard deviation over products and a relatively low standard deviation over persons were considered good items. This final pretest step resulted in six scales comprising in total 52 items.

\section{Data collection for the main study}

Sample A sample was drawn of 495 consumers. All respondents were selected because they owned one of the products that are described in the stimuli section below. The major part of the respondents was part of a consumer panel that consists of 1,700 households from a medium sized Dutch city. A sample of 339 consumers was drawn from the overall panel. These consumers were owners of either intelligent or non-intelligent products. In addition to this panel sample, which was targeted with a mail questionnaire, 156 Dutch consumers were approached via the Internet. All Internet respondents identified themselves as owners of intelligent products via websites such as http:// www.askanowner.com. These respondents were asked to 
fill out an email questionnaire for one specific intelligent product they possessed. Overall, 313 (237 consumer panel and 76 Internet respondents) usable questionnaires were returned, reflecting an effective response rate of $63 \%{ }^{4}$.

Procedure The respondents were approached by phone (members of the consumer panel) or by email (Internet respondents) and were invited to participate in a research project on novel product characteristics. As such, we did not reveal to the respondents that the focus of the study was on product intelligence. Respondents that agreed to participate received a questionnaire by regular mail or by email. Respondents were instructed to fill out the questionnaire on the specific product that they owned (see stimuli section below). Respondents that returned a completed questionnaire were debriefed by mail or email.

Questionnaire The questionnaire consisted of the six scales measuring the product intelligence dimensions and respondents were asked to evaluate the product they owned on each of these dimensions. In addition, measures for relative advantage, compatibility, complexity, and consumer satisfaction were included in the research instrument. The advantage scale was adopted from Cooper and Kleinschmidt (1987) and consisted of five items. The concepts of compatibility and complexity were measured with five items each (based on Rogers 1995). Finally, the scale for consumer satisfaction was based on Hausknecht (1990). The first item in this scale concerns the overall satisfaction with the product. The second item concerns the extent to which the consumer sees the product as the ideal product from the category and is a type of item that can also be found in the American Customer Satisfaction Index (ACSI) (see e.g., Fornell et al. 1996). The third item concerns the extent to which the product matches the consumer's expectations (see also the ACSI for a similar item). This consumer satisfaction item was measured using a seven-point scale where 1 = "much worse than expected" and 7 = "much better than expected." All other items were measured using seven-point Likert scales where $1=$ "totally disagree" and 7 = "totally agree."

Stimuli The respondents evaluated either an intelligent product or a non-intelligent product using the questionnaire. The non-intelligent products were microwave ovens, washing machines, fire alarms, analogue photo cameras, analogue video cameras, and manual lawnmowers. The intelligent products were personal digital assistants (PDAs),

\footnotetext{
${ }^{4}$ The correlations between all variables did not differ significantly at the $p<0.05$-level between the consumer panel and Internet respondents and there was no difference in the signs of the correlations. We therefore combined them in a single sample.
}

navigation systems for walkers, car navigation systems, autonomous lawnmowers, digital photo cameras, digital video cameras, mobile telephones, electronic security systems, personal computers, electronic thermostats, and Sony AIBO robotic dogs. The products were classified as intelligent and non-intelligent by the researchers. Overall, out of the 313 usable questionnaires that were returned, 186 questionnaires concerned intelligent products and 127 questionnaires concerned non-intelligent products.

\section{Measure validaton}

Common method bias Since the measures for all variables were part of one questionnaire, we performed an exploratory factor analysis on all items (for all constructs) to test for common method bias with Harman's one-factor method (Podsakoff and Organ 1986). The results indicated that the first factor accounted for only $23.0 \%$ of the variance indicating that there was no general factor in the unrotated factor structure. These results suggest that there was no major problem of common method bias in the current study.

The product intelligence measure To obtain initial insights on scale dimensionality, we conducted separate exploratory factor analyses to assess the underlying structure of the items of each dimension. Items with high loadings on other factors than the first were dropped from each scale in order to achieve a one factor-solution. Next, we performed a series of confirmatory factor analyses to test the six scales on their unidimensionality. For each subscale, we fitted one-factor models to the data and dropped items that were not unidimensional until we reached a satisfactory fit (see Table 2).

Table 3 reports the psychometric properties of each scale for the six dimensions. The significant factor loadings demonstrate convergent validity, while the Cronbach alphas and construct reliabilities indicate satisfactory internal consistency. Also, all average variance extracted estimates (which assess the amount of variance captured by the construct in relation to the amount of variance due to measurement error) exceeded the minimum level of 0.50 (Fornell and Larcker 1981). The six scales also demonstrate adequate discriminant validity by meeting the criterion that the square of the parameter estimate between two constructs should be less than the average variance extracted estimates of both constructs. These findings support the idea of distinctiveness of the six dimensions.

For each of the six product intelligence dimensions, we computed the mean over the different items; subsequently and consistent with our conceptualization of product intelligence, an overall product intelligence measure was 
Table 2 Fit statistics for all scales (CFA Results)

\begin{tabular}{|c|c|c|c|c|c|c|c|c|}
\hline & Number of items & $\chi^{2}$ & d.f. & $p$ & RMSEA & GFI & NNFI & CFI \\
\hline Autonomy & 4 & 3.43 & 2 & 0.18 & 0.048 & 0.99 & 0.99 & 1.00 \\
\hline Ability to learn & 5 & 4.21 & 5 & 0.52 & 0.000 & 0.99 & 1.00 & 1.00 \\
\hline Reactivity & 4 & 4.59 & 2 & 0.10 & 0.064 & 0.99 & 0.99 & 1.00 \\
\hline Ability to cooperate & 4 & 0.93 & 2 & 0.63 & 0.000 & 1.00 & 1.00 & 1.00 \\
\hline Humanlike interaction & 5 & 2.15 & 5 & 0.83 & 0.000 & 1.00 & 1.01 & 1.00 \\
\hline Personality & 4 & 3.52 & 2 & 0.17 & 0.049 & 0.99 & 0.99 & 1.00 \\
\hline Relative advantage & 3 & 1.17 & 1 & 0.53 & 0.024 & 1.00 & 1.00 & 1.00 \\
\hline Compatibility & 3 & 0.48 & 1 & 0.49 & 0.000 & 1.00 & 1.00 & 1.00 \\
\hline Complexity & 4 & 0.05 & 2 & 0.98 & 0.000 & 1.00 & 1.01 & 1.00 \\
\hline Consumer satisfaction & 3 & 0.79 & 1 & 0.37 & 0.000 & 1.00 & 1.00 & 1.00 \\
\hline
\end{tabular}

For the three-item scales, two of the loadings were specified to be equal to enable testing of the CFA models; this is because a one-factor, three indictor CFA model is just-identified and has zero degrees of freedom.

constructed by weighting the six means using the weights as obtained from the expert study as shown in Table 1 . Finally, the sum of weighted means formed the overall intelligence score. Table 4 shows the means, standard deviations and correlation matrix for all variables in the study.

Known-groups validity An independent samples t-test showed that the non-intelligent products $\left(M_{\text {non-intelligent }}\right.$ products $=61.61$, S.D. $=26.50)$ received significantly lower overall intelligence ratings $(\mathrm{t}-\mathrm{value}=10.24, p<0.05)$ than the intelligent products $\left(M_{\text {intelligent } \text { products }}=93.48\right.$, S.D. $=$ 27.41). This result supports the known-groups validity of the overall product intelligence measure.

The measures for relative advantage, compatibility, complexity, and consumer satisfaction Similar procedures were used to establish the unidimensionality and reliability of the measures for relative advantage, compatibility, complexity and consumer satisfaction. Table 2 shows the fit statistics for the measurement models relating to these variables, while Table 3 shows the items comprising the four scales and their psychometric properties. The high factor loadings demonstrate convergent validity while the Cronbach's alphas, construct reliabilities and average variance extracted estimates all meet recommended criteria. Discriminant validity is also demonstrated by meeting the criterion that the square of the parameter estimate between two constructs should be less than the average variance extracted estimates of both constructs (Fornell and Larcker 1981).

\section{Analysis and results}

We tested our hypotheses with structural equation modeling procedures using LISREL 8.5. The overall product intelli- gence score served as the independent variable. The constructs of relative advantage, complexity and compatibility were represented as latent variables indicated by their corresponding indicators, as was the consumer satisfaction measure.

We followed Baron and Kenny (1986) in testing the mediating hypotheses $\mathrm{H}_{1 \mathrm{a}}-\mathrm{H}_{1 \mathrm{c}}$. According to these authors, three conditions have to be met for mediation. In the first model, the independent variable (product intelligence in this case) must affect the mediators (here, relative advantage, compatibility and complexity). In the second model, the independent variable (product intelligence) must affect the dependent variable (consumer satisfaction). In the third model, the mediators must affect the dependent variable and the effect of the independent variable on the dependent variable must be less than in the second model. Perfect mediation is obtained when the independent variable has no effect on the dependent variable (i.e., is non-significant) when the mediators are included in the analysis. We estimated the three models to test whether our data meets the three criteria of Baron and Kenny (1986) and concluded with the fourth and hypothesized (perfect mediational) model in which hypotheses $\mathrm{H}_{2 \mathrm{a}}-\mathrm{H}_{2 \mathrm{c}}$ and $\mathrm{H}_{3 \mathrm{a}}-\mathrm{H}_{3 \mathrm{c}}$ were tested. Table 5 shows the fit statistics for all four models.

In the first model, we estimated the direct effect of product intelligence on the innovation attributes of relative advantage, compatibility and complexity. The results revealed that product intelligence had a positive significant effect on relative advantage $(\gamma=0.39, t$-value $=6.68)$, compatibility $(\gamma=0.22, t$-value $=3.76)$, and complexity $(\gamma=0.20$, $t$-value $=3.15)$. In the second model we estimated the direct effect of product intelligence on consumer satisfaction. This model showed that product intelligence had a significant positive effect on consumer satisfaction $(\gamma=0.22, t$-value $=$ 3.41). In the third (partially mediational) model we estimated the direct effects of product intelligence on relative advantage, compatibility, complexity, and consumer 
Table 3 The measures and their psychometric properties

\begin{tabular}{|c|c|c|c|}
\hline Dimensions & Items "this product......." & Factor loadings & $t$-values \\
\hline \multirow[t]{5}{*}{ Autonomy } & $(\alpha=0.81 \mathrm{CR}=0.82 \mathrm{AVE}=0.53)$ & & \\
\hline & 1. determines itself how it conducts tasks & 0.56 & 9.93 \\
\hline & 2. takes decisions by itself & 0.86 & 16.97 \\
\hline & 3. takes the initiative & 0.80 & 15.40 \\
\hline & 4. does things by itself & 0.66 & 12.23 \\
\hline \multirow[t]{6}{*}{ Ability to learn } & $(\alpha=0.91 \mathrm{CR}=0.92 \mathrm{AVE}=0.69)$ & & \\
\hline & 1. can learn & 0.71 & 14.25 \\
\hline & 2. performs better and better & 0.81 & 17.18 \\
\hline & 3. learns from experience & 0.95 & 22.23 \\
\hline & 4. improves itself & 0.88 & 19.37 \\
\hline & 5. adapts itself over time & 0.77 & 15.83 \\
\hline \multirow[t]{5}{*}{ Reactivity } & $(\alpha=0.89 \mathrm{CR}=0.89 \mathrm{AVE}=0.67)$ & & \\
\hline & 1. acts on the basis of observations & 0.74 & 14.69 \\
\hline & 2. keeps an eye on its environment & 0.83 & 17.15 \\
\hline & 3. reacts to changes & 0.84 & 17.56 \\
\hline & 4. directly adapts its behavior to the environment & 0.85 & 17.97 \\
\hline \multirow{5}{*}{$\begin{array}{l}\text { Ability to } \\
\text { cooperate }\end{array}$} & $(\alpha=0.88 \mathrm{CR}=0.89 \mathrm{AVE}=0.68)$ & & \\
\hline & 1. can cooperate with other products & 0.91 & 20.45 \\
\hline & 2. communicates with other products & 0.92 & 20.78 \\
\hline & 3. can be connected with other products & 0.85 & 18.31 \\
\hline & 4. works better in cooperation with other products & 0.56 & 10.46 \\
\hline \multirow{6}{*}{$\begin{array}{l}\text { Humanlike } \\
\text { interaction }\end{array}$} & $(\alpha=0.85 \mathrm{CR}=0.85 \mathrm{AVE}=0.54)$ & & \\
\hline & 1. consults the user & 0.67 & 12.63 \\
\hline & 2. assists the user & 0.70 & 13.49 \\
\hline & 3. starts a dialogue with the user & 0.83 & 17.09 \\
\hline & 4. explains to the user how it should be used & 0.83 & 16.95 \\
\hline & 5. explains what it is doing & 0.60 & 11.00 \\
\hline \multirow[t]{5}{*}{ Personality } & $(\alpha=0.79 \mathrm{CR}=0.81 \mathrm{AVE}=0.52)$ & & \\
\hline & 1. has human properties & 0.80 & 15.19 \\
\hline & 2. has its own character & 0.74 & 13.88 \\
\hline & 3. is like a person & 0.76 & 14.26 \\
\hline & 4. behaves like a human being & 0.57 & 10.09 \\
\hline \multirow{4}{*}{$\begin{array}{l}\text { Relative } \\
\text { advantage }\end{array}$} & $(\alpha=0.86, \mathrm{CR}=0.86, \mathrm{AVE}=0.68)$ & & \\
\hline & 1. offers advantages that are not offered by competing products & 0.81 & 20.98 \\
\hline & 2. is, in my eyes, superior to competing products & 0.90 & 20.98 \\
\hline & 3. solves a problem that I cannot solve with competing products & 0.76 & 15.05 \\
\hline \multirow[t]{4}{*}{ Compatibility } & $(\alpha=0.87, \mathrm{CR}=0.88, \mathrm{AVE}=0.71)$ & & \\
\hline & 1. fits into my way of living & 0.77 & 18.54 \\
\hline & 2. fits the way I do things & 0.80 & 18.54 \\
\hline & 3. suits me well & 0.95 & 20.43 \\
\hline \multirow[t]{5}{*}{ Complexity } & $(\alpha=0.82, \mathrm{CR}=0.85, \mathrm{AVE}=0.60)$ & & \\
\hline & 1. is complicated for a lot of people & 0.46 & 8.11 \\
\hline & 2. How much knowledge is needed to use your product? & 0.85 & 17.78 \\
\hline & 3. How much help is needed in taking your product into use? & 0.87 & 18.53 \\
\hline & 4. How much effort do you think it costs to learn how to use your product? & 0.85 & 17.97 \\
\hline Consumer & $(\alpha=0.76, \mathrm{CR}=0.78, \mathrm{AVE}=0.55)$ & & \\
\hline \multirow[t]{3}{*}{ Satisfaction } & 1. I am very satisfied with my product. & 0.83 & 18.02 \\
\hline & 2. This product matches my ideal product in the product category & 0.70 & 18.02 \\
\hline & $\begin{array}{l}\text { 3. What is your general experience with the product? }(1=\text { "much worse than expected," } \\
7=\text { "much better than expected") }\end{array}$ & 0.68 & 11.97 \\
\hline
\end{tabular}

$\alpha=$ Cronbach's alpha, $\mathrm{CR}=$ Composite Reliability, AVE $=$ Average Variance Extracted 
Table 4 Descriptive statistics and correlations $(n=313)$

\begin{tabular}{|c|c|c|c|c|c|c|c|c|c|c|c|}
\hline Variables & AU & AL & $\mathrm{R}$ & $\mathrm{AC}$ & $\mathrm{HI}$ & $P$ & RA & $\mathrm{CP}$ & CL & $\mathrm{CS}$ & PI \\
\hline Mean & 3.03 & 1.91 & 2.71 & 3.62 & 2.90 & 1.52 & 3.04 & 4.89 & 3.23 & 4.74 & 80.55 \\
\hline Standard deviation & 1.68 & 1.35 & 1.87 & 2.09 & 1.53 & 0.53 & 1.62 & 1.48 & 1.35 & 1.24 & 31.22 \\
\hline Autonomy (AU) & - & & & & & & & & & & \\
\hline Ability to Learn (AL) & $0.11 *$ & - & & & & & & & & & \\
\hline Reactivity (R) & $0.42 *$ & $0.22 *$ & - & & & & & & & & \\
\hline Ability to Cooperate (AC) & $0.12 *$ & $0.42 *$ & $0.13 *$ & - & & & & & & & \\
\hline Humanlike Interaction (HI) & $0.20 *$ & $0.53 *$ & $0.17 *$ & $0.52 *$ & - & & & & & & \\
\hline Personality $(\mathrm{P})$ & $0.14 *$ & $0.44 *$ & $0.33 *$ & $0.24 *$ & $0.42 *$ & - & & & & & \\
\hline Relative Advantage (RA) & $0.16^{*}$ & $0.27 *$ & $0.16^{*}$ & $0.32 *$ & $0.29 *$ & $0.32 *$ & - & & & & \\
\hline Compatibility (CP) & 0.10 & $0.19 *$ & 0.10 & $0.19^{*}$ & $0.30 *$ & $0.17 *$ & $0.31 *$ & - & & & \\
\hline Complexity (CL) & 0.04 & $0.23 *$ & 0.00 & $0.21 *$ & $0.26^{*}$ & $0.13 *$ & -0.02 & $-0.15^{*}$ & - & & \\
\hline Consumer Satisfaction (CS) & $0.14 *$ & 0.10 & $0.11^{*}$ & $0.15^{*}$ & $0.22 *$ & 0.10 & $0.39 *$ & $0.65^{*}$ & $-0.16^{*}$ & - & \\
\hline Product Intelligence (PI) & $0.59 *$ & $0.68 *$ & $0.63^{*}$ & $0.66^{*}$ & $0.68^{*}$ & $0.55 *$ & $0.37 *$ & $0.24^{*}$ & $0.20^{*}$ & $0.21 *$ & - \\
\hline
\end{tabular}

${ }^{*} p<0.05$. All mean entries, other than for product intelligence, are based on a 7-point scale.

satisfaction and the effects of relative advantage, compatibility and complexity on consumer satisfaction. This model showed that (in comparison to the second model) the direct effect of product intelligence on consumer satisfaction had become insignificant $(\gamma=-0.04, t$-value $=-0.69)$. Product intelligence showed a positive significant effect on relative advantage $(\gamma=0.39, t$-value $=6.58)$, compatibility $(\gamma=0.22$, $t$-value $=3.72)$, and complexity $(\gamma=0.20, t$-value $=3.15)$. Relative advantage $(\beta=0.31, t$-value $=5.19)$, compatibility $(\beta=$ $0.72, t$-value $=9.30)$, and complexity $(\beta=-0.10, t$-value $=-1.88)$ were significantly associated with consumer satisfaction. These results support hypotheses $\mathrm{H}_{1 \mathrm{a}}-\mathrm{H}_{1 \mathrm{c}}$ which state that the effect of product intelligence on consumer satisfaction is fully mediated by relative advantage, compatibility, and complexity.

We estimated the fourth and hypothesized (perfect mediational) model to test hypotheses $\mathrm{H}_{2 \mathrm{a}}-\mathrm{H}_{2 \mathrm{c}}$ and $\mathrm{H}_{3 \mathrm{a}}-\mathrm{H}_{3 \mathrm{c}}$ (see Fig. 1). Specifically, we estimated the direct effects of product intelligence on relative advantage, compatibility and complexity and the direct effects of these latter three variables on consumer satisfaction (i.e., we eliminated the direct link from product intelligence to consumer satisfaction). Product intelligence showed a positive significant effect on relative advantage $(\gamma=0.39, t$-value $=6.56)$, compatibility $(\gamma=0.22, t$-value $=3.68)$, and complexity $(\gamma=0.20$, $t$-value=3.16). Thus, hypotheses $\mathrm{H}_{2 \mathrm{a}}, \mathrm{H}_{2 \mathrm{~b}}$, and $\mathrm{H}_{2 \mathrm{c}}$ were all confirmed. Hypotheses $\mathrm{H}_{3 \mathrm{a}}$ and $\mathrm{H}_{3 \mathrm{~b}}$ were also supported as relative advantage $(\beta=0.29, t$-value $=5.36)$ and compatibility $(\beta=0.72, t$-value $=9.36)$ had significant positive effects on consumer satisfaction. Complexity was found to have a negative significant effect on consumer satisfaction $(\beta=$ $-0.11, t$-value $=-2.06$ ), providing support for hypothesis $\mathrm{H}_{3 \mathrm{c}}$.

\section{Discussion}

We introduce the new construct of product intelligence and conceptualize it as consisting of six dimensions: autonomy, ability to learn, reactivity, ability to cooperate, humanlike interaction, and personality. Along with this conceptualization we develop and test an operational measure for the construct of product intelligence. To investigate how product intelligence is related to consumers' product evaluations we examine the impact of product intelligence on the central construct of consumer satisfaction through the innovation attributes of relative advantage, compatibility and complexity. We show that this impact is fully mediated by the innovation attributes of relative advantage, compatibility, and complexity. Specifically, product intelligence has a positive impact on relative advantage and compatibility, which, in turn, both positively affect consumer satisfaction. These findings suggest that consumers appreciate products not for their intelligence itself, but

Table 5 Fit statistics for the different estimated models

\begin{tabular}{|c|c|c|c|c|c|c|c|}
\hline Model & $\chi^{2}$ & d.f. & $p$ & RMSEA & GFI & NNFI & CFI \\
\hline 1. Product Intelligence $\rightarrow$ Innovation Attributes & 87.64 & 42 & 0.00 & 0.059 & 0.95 & 0.96 & 0.97 \\
\hline 2. Product Intelligence $\rightarrow$ Consumer Satisfaction & 4.69 & 2 & 0.10 & 0.066 & 0.99 & 0.97 & 0.99 \\
\hline 3. Partially mediational model & 136.66 & 71 & 0.00 & 0.054 & 0.94 & 0.96 & 0.97 \\
\hline 4. Perfect mediational model & 137.35 & 72 & 0.00 & 0.054 & 0.94 & 0.96 & 0.97 \\
\hline
\end{tabular}


Fig. 1 Standardized estimates for the hypothesized model. $* p<0.05$.

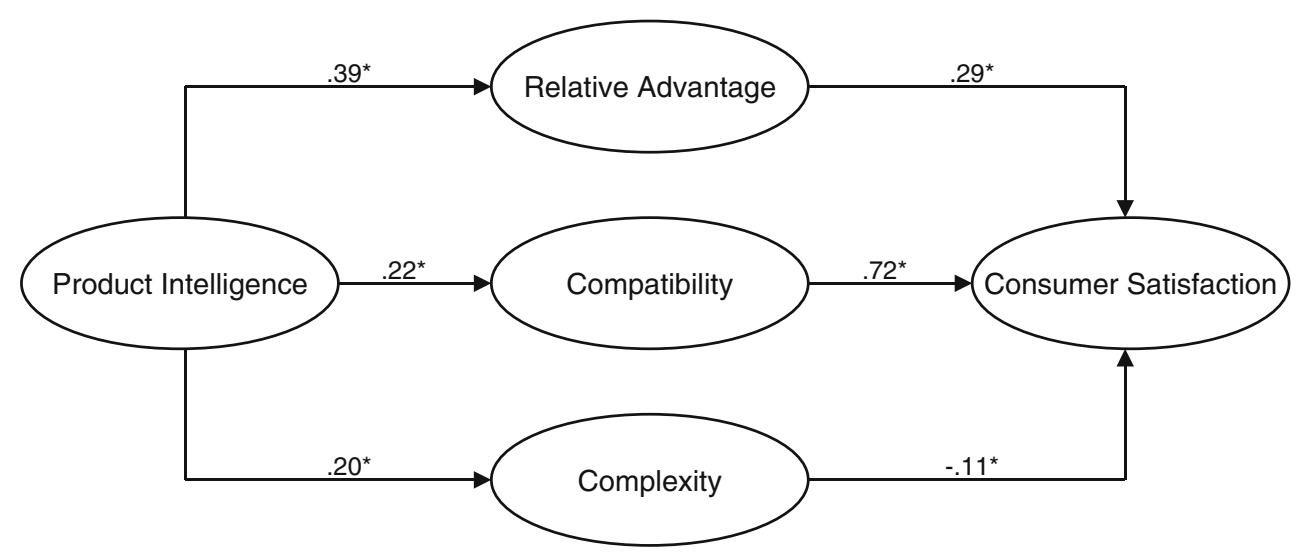

because of the resultant relative advantage and compatibility they perceive in them. Product intelligence also positively influences perceived complexity, which, however, has a negative impact on consumer satisfaction. This result suggests that consumers are less satisfied with products with a higher intelligence because of their complexity.

Implications for practice

Our study offers several opportunities and implications for practitioners working in new product development and marketing. Our conceptualization of product intelligence may play a role in new product ideation. Previous research has shown that analogical thinking results in more original product ideas (Dahl and Moreau 2002). Analogical thinking implies that existing, familiar information from one domain is transferred to the other. As such, design team members may use the conceptualization of product intelligence by projecting it on their own product domain and use it for the construction of new product ideas. Design team members could generate ideas on how they can make their products, for example, more autonomous, reactive or better able to learn. As with all new product ideas the quality of these ideas should subsequently be thoroughly tested. However, combining the conceptualization of product intelligence with analogical thinking may result in more creative ideas for new intelligent products.

Our results show that consumers do not appreciate intelligent products for their intelligence itself, but because of the relative advantage and compatibility that they deliver. Also, consumers have a lower appreciation for intelligent products when they perceive these products as more complex. Product intelligence has a relatively strong effect on relative advantage. The application of chips and software delivers improved or new functionality to a product, which makes it superior to competing products. Of course, it remains important that this functionality is based on customer information and is clearly linked with specific customer needs, as is encouraged in the marketing literature. An increase in product intelligence also goes along with an increase in product compatibility. This finding indicates that more intelligent products are better adapted to their users. Just like human and animal intelligence are described as the ability to adapt to the environment, this also seems to be the case for intelligent products. Products that are able to interact with the user in a humanlike way are more compatible with existing mental frameworks of potential adopters; hence adopters have to put less effort in learning how to use these products. Also, products that are more autonomous, able to learn or reactive can be less demanding for users and approach a level of symbiosis in which interaction with their users becomes more natural or even invisible.

Along with an increase in relative advantage and compatibility, product intelligence also moderately increases the complexity that consumers perceive. However, certain marketing techniques may reduce such complexity. Research shows, for instance, that using consumers' existing knowledge structures in promotional messages facilitates consumer understanding (Gregan-Paxton and John 1997). As such, The Ford Motor Company explains the benefits of its Intelligent Protection System by using the picture of a guardian angel in a print advertisement. The guardian angel is part of the existing knowledge structure of consumers that helps consumers understand the protection system. Increased understanding will lead to a decrease in perceived complexity and a greater likelihood to adopt the product.

\section{Implications for theory}

This paper expands marketing theory by elucidating the construct of product intelligence and conceptualizing it as being formed out of the six dimensions of autonomy, ability to learn, reactivity, ability to cooperate, humanlike interaction, and personality. Our definition of product intelligence joins in with the literature predicting that intelligence will 
be added to everyday entities by connecting them with the ubiquitous network (Watson et al. 2004; Zinkhan 2005). Embedding consumer products within this network may shift the existing ideas on the interface between firms and consumers. The usefulness and information-providing capacity of consumer durables will increase (Watson et al. 2004) and consumer durables will evolve from end products to extensions of companies' market interfaces. Because of their connection to the ubiquitous network, consumer durables will become important sources of information on patterns of user behavior in terms of, for example, use frequency or functionality that they do (or do not) make use of. Vice-versa, consumer durables will become new media for marketing communications. Firms will be able to directly approach their customers through the interfaces of their consumer durables with, for example, promotional messages.

Our study shows that product intelligence influences consumer satisfaction through relative advantage, compatibility, and complexity. This indicates that technology is a means and not an end. Also, the finding that higher levels of intelligence are associated with higher levels of perceived complexity indicates that contemporary intelligent products absorb user attention in an inefficient manner. Nowadays, most products are operated through complex physical interfaces. More frequent use of, for example, speech technology (humanlike interaction) may reduce this complexity and ensure that input from the user is more efficiently converted into added value (Watson et al. 2004). The positive effects of product intelligence on both relative advantage and compatibility are in accordance with the theory that technology may create value by reducing the necessity of consciously interacting with phenomena (Watson et al. 2004). While, for example, traditional vacuum cleaners and lawnmowers do not deliver value without continuous input from their user, autonomous lawnmowers and vacuum cleaners enable consumers to spend time on other activities while these products do their work. Overall, product intelligence appears to have a clear payoff in itself.

Furthermore, we theorize that, along with the increasing intelligence of consumer durables, consumers' perceptions of these artifacts may be changing. Products with higher levels of autonomy or the ability to learn are likely to take over a substantial number of physical and mental tasks from their owners. As such, the responsibility of consumer products increases and their importance grows. Also, consumers' way of looking and evaluating products may change. Instead of being simple tools that can help in fulfilling consumer needs, consumer durables are evolving into sophisticated agents that assist consumers in multiple aspects of their daily life. As such, consumers' purchase decisions may become increasingly complex and important.
Limitations

Like most studies, the present study suffers from certain limitations. Although we collect product evaluations from product owners because of their product expertise, we should realize that a majority of the respondents already owned an intelligent product and may therefore be positively biased towards the products that they evaluated. Also, all products that were evaluated in this study had already been introduced into the marketplace. As such, the companies that developed these products probably expected them to have a certain market potential. The degree to which our results can be generalized to other consumer segments and to intelligent products that have not yet been introduced into the marketplace therefore remains to be empirically investigated.

Further research

One important future research direction is to investigate consumer perceptions of intelligent products in pre-purchase situations. Such research could provide more insight into the factors that determine consumers' willingness to purchase intelligent products. On the one hand, the attention-drawing character of some intelligent products may be appealing to consumers. On the other hand, the functionality of intelligent products mainly follows from IT. As a result, the advantages of intelligent products are not clearly observable (Norman 1998). According to adoption theory, innovations with less observable advantages diffuse at a slower rate (Rogers 1995).

Another topic for future research may be the attentiondrawing character of intelligent products. Because of this character, intelligent products may serve as icons for the company, which symbolize what the company is capable of with respect to product innovation. Making products more intelligent means that there sometimes appears to be a 'ghost in a machine.' Previous research shows that consumers provide more positive product evaluations as a result of surprise and arousal effects elicited by these products (Vanhamme and Snelders 2001). Similarly, the attentiondrawing character of product intelligence may be interesting for branding and corporate public relations for companies that operate in the consumer electronics industry. Sony is, for example, doing this with the aforementioned AIBO. The robotic dog exemplifies most of the dimensions of product intelligence, which results in a range of impressive capabilities. Also, the Honda Corporation is developing the Humanoid Robot ASIMO (world.honda. com). Honda currently uses the most advanced version of this robot, the $\mathrm{P} 3$, for publicity purposes by letting it travel around the world to meet prominent people such as European politicians and Olympic medalists. With its 
intelligent robot, Honda further strengthens its image as a technological leader. Future research could, for example, investigate which product intelligence dimensions contribute mostly to the attention-drawing character of these products.

Finally, it would also be interesting to investigate whether adopters of intelligent products have special characteristics. In this study we did not take respondents' characteristics such as social class, lifestyle, or values into account. However, previous research shows that consumers with a higher level of desire for control perceive less risk in autonomous products than consumers with a low desire for control (Rijsdijk and Hultink 2003). Possibly, other consumer characteristics play a role in intelligent product adoption as well. Older consumers may have difficulty adopting these complex products because of decreasing learning and problem-solving capabilities (Gregoire 2003). In contrast, consumers with higher levels of self-efficacy regarding the operation of technologically advanced products may be more likely to adopt intelligent products, as it has been shown to be the case for a technology-based selfservice (Dabholkar and Bagozzi 2002). Research into this issue would be interesting for the determination of target groups for intelligent products. It may also stimulate companies to create products that are sufficiently intelligent to satisfy all consumer segments.

Acknowledgements The authors gratefully acknowledge the helpful comments by George M. Zinkhan, the editor, and three anonymous reviewers. Furthermore, the authors acknowledge the Product Development and Management Association (PDMA) and the Netherlands Organization for Scientific Research (NWO) for financing parts of this research project. Also, they thank Jetske Bouma and Bas van de Werk for contributing to this project.

\section{References}

Alpert, S. R., Karat, J., Karat, C. M., Brodie, C., \& Vergo, J. G. (2003). User attitudes regarding a user-adaptive ecommerce web site. User Modeling and User-Adapted Interaction, 13, 373-396.

Baber, C. (1996). Humans, servants and agents: Human factors of intelligent products. In Proceedings of the conference on artificial intelligence in consumer and domestic products. London: IEE

Baron, R. M., \& Kenny, D. A. (1986). The moderator-mediator variable distinction in social psychological research: Conceptual, strategic, and statistical considerations. Journal of Personality and Social Psychology, 51, 1173-1182, (December).

Bauer, S., \& Mead, P. (1995). After you open the box: Making smart products more usable, useful, and desirable through interactive technology. Design Management Journal, 6, 21-27.

Bradshaw, J. M. (1997). Software agents. Menlo Park, CA: American Association for Artificial Intelligence.

Burgoon, J. K., Bonito, J. A., Bengston, B., Cederberg, C., Lundeberg, M., \& Allspach, L. (2000). Interactivity in human- computer interaction: A study of credibility, understanding, and influence. Computers in Human Behavior, 16, 553-574.

Cassell, J., \& Thorisson, K. R. (1999). The power of a nod and a glance: Envelope vs. emotional feedback in animated conversational agents. Applied Artificial Intelligence, 13, 519-538.

Chan, F. Y., \& Khalid, H. M. (2003). Is talking to an automated teller machine more natural and fun? Ergonomics, 46, 1386-1407.

Cooper, R. G., \& Kleinschmidt, E. J. (1987). New products: What separates winners from losers? Journal of Product Innovation Management, 4, 169-184.

Dabholkar, P. A., \& Bagozzi, R. P. (2002). An attitudinal model of technology-based self-service: Moderating effects of consumer traits and situational factors. Journal of the Academy of Marketing Science, 30, 184-201.

Dahl, W. D., \& Moreau, P. (2002). The influence and value of analogical thinking during new product ideation. Journal of Marketing Research, 34, 47-60.

Den Buurman, R. (1997). User-centered design of smart products. Ergonomics, 40, 1159-1169.

Dhebar, A. (1996). Information technology and product policy: 'Smart' products. European Management Journal, 14, 477-485.

Fornell, C., Johnson, M. D., Anderson, E.W., Cha, J., \& Bryant, B. E. (1996). The American customer satisfaction index: Nature, purpose, and findings. Journal of Marketing, 60, 7-18.

Fornell, C., \& Larcker, D. F. (1981). Evaluating structural equation models with unobservable variables and measurement error. Journal of Marketing Research, 18, 39-50.

Gregan-Paxton, J., \& John, D. R. (1997). Consumer learning by analogy: A model of internal knowledge transfer. Journal of Consumer Research, 24, 266-284.

Gregoire, Y. (2003). The impact of aging on consumer responses: What do we know? Advances in Consumer Research, 30, 19-26.

Han, S. H., Yun, M. H., Kwahk, J., \& Hong, S. W. (2001). Usability of consumer electronic products. International Journal of Industrial Ergonomics, 28, 143-151.

Hausknecht, D. R. (1990). Measurement scales in consumer satisfaction/dissatisfaction. Journal of Consumer Satisfaction, Dissatisfaction and Complaining Behavior, 3, 1-9.

Homburg, C., \& Stock, R. M. (2004). The link between salespeople's job satisfaction and customer satisfaction in a business-to-business context: A dyadic analysis. Journal of the Academy of Marketing Science, 32, 144-158.

Jarvis, C. B., MacKenzie, S. B., \& Podsakoff, P. M. (2003). A critical review of construct indicators and measurement model misspecification in marketing and consumer research. Journal of Consumer Research, 30, 199-218.

Katz, M. L., \& Shapiro, C. (1985). Network externalities, competition, and compatibility. American Economic Review, 75, 424-440.

Law, K. S., Wong, C.-S., \& Mobley, W. M. (1998). Toward a taxonomy of multidimensional constructs. The Academy of Management Review, 23, 741-755.

Mano, H., \& Oliver, R. L. (1993). Assessing the dimensionality and structure of the consumption experience: Evaluation, feeling and satisfaction. Journal of Consumer Research, 20, 451-466.

Murasaki, Y. (2001). TV program selection based on a user model agent. In AI2001-50: NHK Science \& Technical Research Laboratories.

Nicoll, D. (1999). Taxonomy of information intensive products. Edinburgh: The University of Edinburgh Management School (working paper).

Norman, D. A. (1998). The design of everyday things (1st ed.). London, England: MIT Press.

Nwana, H. S., \& Ndumu, D. T. (1997). An introduction to agent technology. In H. S. Nwana \& N. Azarmi (Eds.), Software agents and soft computing: Towards enhancing machine intelligence. Berlin: Springer. 
Oliver, R. L. (1993). Cognitive, affective, and attribute bases on the satisfaction response. Journal of Consumer Research, 20, 418-430.

Plouffe, C. R., Vandenbosch, M., \& Hulland, J. (2001). Intermediating technologies and multi-group adoption: A comparison of consumer and merchant adoption intentions toward a new electronic payment system. Journal of Product Innovation Management, 18, 65-81.

Podsakoff, P. M., \& Organ, D. W. (1986). Self-reports in organizational research: Problems and prospects. Journal of Management, $12,531-543$

Rijsdijk, S. A., \& Hultink, E. J. (2003). Honey, have you seen our hamster? Consumer evaluations of autonomous domestic products. Journal of Product Innovation Management, 20, 204-216.

Rogers, E. M. (1995). Diffusion of innovations (4th ed.). New York: Free.

Shrout, P. E., \& Fleiss, J. L. (1979). Intraclass correlations: Uses in assessing rater reliability. Psychological Bulletin, 86, 420-428.

Spreng, R. A., \& Olshavsky, R. W. (1993). A desires congruency model of consumer satisfaction. Journal of the Academy of Marketing Science, 21, 169-178.

Sproull, L., Subramani, M., Kiesler, S., Walker, J. H., \& Waters, K. (1996). When the interface is a face. Human-Computer Interaction, 11(2), 97-124.

Szymanski, D. M., \& Henard, D. H. (2001). Consumer satisfaction: A meta-analysis of the empirical evidence. Journal of the Academy of Marketing Science, 29, 16-35.
Tornatzky, L., \& Klein, K. J. (1982). Innovation characteristics and innovation adoption-implementation: A meta-analysis of findings. IEEE Transactions on Engineering Management, 29, 28-45.

Vanhamme, J., \& Snelders, D. (2001). The role of surprise in satisfaction judgements. Journal of Consumer Satisfaction, Dissatisfaction and Complaining Behavior, 14, 27-45.

Waern, A. (2004). User involvement in automatic filtering: An experimental study. User Modeling and User-adapted Interaction, 14, 201-237.

Watson, R. T., Berthon, P., Pitt, L. F., \& Zinkhan, G. M. (2004). Marketing in the age of the network: From marketplace to u-space. Business Horizons, 47, 33-40.

Watson, R. T., Pitt, L. F., Berthon, P., \& Zinkhan, G. M. (2002). Ucommerce: Expanding the universe of marketing. Journal of the Academy of Marketing Science, 30, 333-347.

Wirtz, J., \& Mattila, A. (2001). Exploring the role of alternative perceived performance measures and needs-congruency in the consumer satisfaction process. Journal of Consumer Psychology, $11,181-192$.

Zinkhan, G. M. (2003). A look to the future of jams: Three years out, thirty years out. Journal of the Academy of Marketing Science, $31,225-228$.

Zinkhan, G. M. (2005). The marketplace, emerging technology and marketing theory. Marketing Theory, 5, 105-115. 